\title{
ANÁLISE DA PERCEPÇÃO DA QUALIDADE NO ENSINO SUPERIOR: UMA VISÃO DOS DISCENTES DO CURSO DE ENGENHARIA DE PRODUÇÃO DA UFERSA CAMPUS ANGICOS
}

Marcelo Miguel Moura de Medeiros - marcelommm1@live.com

Universidade Federal Rural do Semi-Árido

Rua Gamaliel Martins Bezerra,

59515-000 - Angicos - Rio Grande do Norte

Rafael de Azevedo Palhares - rafaelpalhareseng@hotmail.com

Universidade Federal Rural do Semi-Árido

Rua Gamaliel Martins Bezerra,

59515-000 - Angicos - Rio Grande do Norte

Natália Veloso Caldas de Vasconcelos-natalia.vasconcelos@ufersa.edu.br

Universidade Federal Rural do Semi-Árido

Rua Gamaliel Martins Bezerra,

59515-000 - Angicos - Rio Grande do Norte

Resumo: A avaliação da qualidade do ensino superior sob a ótica do discente, é um fator chave para a gestão acadêmica de cursos de graduação e de instituições de ensino. Neste contexto, o presente estudo tem o objetivo de analisar a percepção do curso de Engenharia de Produção na visão dos discentes. A classificação metodológica da pesquisa quanto ao seu caráter é definida como pesquisa de campo, na qual foi elaborado e aplicado um questionário online que atingiu 95\% do seu público alvo, com o intuito de analisar o grau de satisfação dos discentes em relação ao corpo docente, infraestrutura e grade curricular. Esta avaliação permitiu identificar uma perspectiva da educação do ensino superior, com ênfase ao curso de engenharia de produção da UFERSA Campus Angicos de modo que o grau de satisfação do discente em relação a atuação dos docentes, infraestrutura e a grade curricular sejam apresentados.

Palavras-chave: Ensino superior. Engenharia de Produção. Discentes. Avaliação.

\section{INTRODUÇÃO}

A Educação superior vem dando vastas demonstrações de sua importância para que hajam transformações importantes na sociedade; estudos mostram que o desenvolvimento requer cada vez mais a ampliação dos níveis de escolaridade da população com isso a sociedade atual exige e necessita que as pessoas tenham um novo perfil que contenham flexibilidade, agilidade e uma fácil adequação para os sistemas produtivos que estão em constante mudança.

De acordo com Bertolin (2007), nas décadas de 1960 e 1970, a preocupação com a educação se dava, basicamente, no sentido quantitativo e foi na década de 1980 que começaram a surgir, nos EUA e na Europa, as primeiras reflexões acerca da qualidade da educação.

A expressão "qualidade em educação", segundo Davok (2007), admite variadas interpretações. Segundo essa autora, uma educação de qualidade vai desde aquela que possibilita o domínio eficaz dos conteúdos, ou aquela que possibilita a aquisição de uma cultura 
científica ou literária, até aquela que desenvolve a capacidade de servir ao sistema produtivo ou ainda aquela que promove o espírito crítico e fortalece o compromisso para transformar a realidade social.

Várias informações são indispensáveis para quem quer implantar uma melhoria contínua no ensino superior seja em um ambiente próximo ou distante, observações que são indispensáveis para se fazer essa avaliação seriam: avaliação da qualidade do curso com base na contribuição da formação acadêmica para a vida profissional, inserção no mercado de trabalho, satisfação profissional e perfil profissional.

O presente trabalho fará uma análise da percepção da qualidade no curso superior de Engenharia de produção da Universidade Federal Rural do Semi-Árido na visão dos discentes para que o corpo docente possa ver onde estão seus pontos fortes e fracos com a finalidade se obter um processo de melhoria continua e com isso aprimorando cada vez mais os seus métodos e consequentemente o curso como um todo.

Este trabalho apresenta a seguinte estrutura: na seção um, uma contextualização do tema a ser seguido, no tópico dois, a fundamentação teórica, sendo abordados assuntos como gestão da qualidade, qualidade no serviço e qualidade no ensino superior, na terceira seção apresentase a metodologia da pesquisa, na seção seguinte mostra-se os resultados e discussões. Por fim, as considerações conclusivas da pesquisa e referências bibliográficas.

\section{REFERENCIAL TEÓRICO}

\subsection{Gestão da Qualidade}

A Gestão da qualidade quando utilizada como estratégia de vantagem competitiva das empresas, precisa ter como foco que o cliente é a chave para a conquista e manutenção do mercado, pois com essa percepção será possível fazer a identificação dos requisitos e expectativas dos seus clientes consumidores e com isso oferecer valor ao mercado (CARPINETTI, 2012).

Segundo Moreira et al. (2014), "qualidade é tudo aquilo que aprimora o produto na vista do cliente. Somente o cliente tem a capacidade de fazer a definição do que é a qualidade do um produto. A visão de qualidade muda de acordo com a percepção do que seja qualidade de cliente para cliente".

Destaca-se a importância das medidas de qualidade, tendo em vista o papel decisivo por elas assumido em face dos processos de globalização, a abertura dos mercados e da consequente competição entre organizações (CORRỂA, 2002).

De acordo com Queiroz (2011) com o aumento na procura de vagas para os cursos de graduação e pós-graduação, ocorre também um crescimento na concorrência das IES, onde novas instituições são criadas e consequentemente novos cursos oferecidos.

Os indicadores de qualidade fazem parte do mundo da gestão da qualidade e com isso elas possibilitam o ininterrupto aprimoramento dos serviços, que a todo instante são obrigadas a ter novas alterações a fim de uma melhor satisfação do cliente (FITZSIMMONS, 2004).

\subsection{Gestão da qualidade em serviços}

Para conseguir a satisfação dos seus clientes, as empresas devem ter laços com o seu cliente a fim de que eles sempre se interessem pelos seus serviços. Associar a qualidade do serviço com os laços com o cliente pode ser uma solução para essa problemática. O trabalho comprometido com a excelência do atendimento ao cliente é essencial (DINIZ, 2008).

O entusiasmo dos clientes deve ser uma ação de estratégia que as organizações devem atingir, segundo Rangel (1995 apud FURTADO, 2008) a "a qualidade voltada na satisfação do 
cliente é um conceito de estratégia que as empresas têm de pôr para reter os clientes e conquistar novo mercado".

Para ter o melhor entendimento das atividades que envolvem serviços inicialmente tem de se compreender as definições de serviços. Segundo Troster (1999 apud FERNANDO, MACHADO e QUEIROZ, 2006), serviços são apresentados como "atividades que criam ou não objetos matérias, mas se destinam direta ou indiretamente a satisfazer as necessidades humanas".

De acordo com Campos (2014), um produto ou serviço de qualidade é notado por ser aquele produto que atende com excelência, de forma honesta, alcançável, segura todas às necessidades dos clientes.

Para Juran (1992), a qualidade em serviços, é a capacidade de que o serviço corresponda de forma razoável às necessidades do cliente quando esse serviço for prestado.

É de extrema importância que os usuários percebam o valor deste serviço prestado, pois a sobrevivência dessas empresas prestadores de serviços dependem do seu reconhecimento. Em um cenário cada vez mais competitivo, as empresas precisam de sempre avaliar a sua qualidade e implantar a melhoria contínua para que cada vez mais gere uma melhor satisfação ao usuário.

\subsection{Ensino superior e Engenharia de Produção no Brasil}

Educação superior é exposta a um conjunto de demandas que incertamente podem ser atendidas, dentre essa e mais causas são motivos para que a sociedade brasileira vem passando por várias adequações ao longo dos anos (DIAS SOBRINHO, 2010).

Instituições de ensino superior, seja pública ou privada, ofertam as mesmas graduações e os mesmos diplomas profissionais. Com isso, tem-se a popularização do diploma de ensino superior, no entanto, isso não ocorre com a qualidade do ensino (DURHAM, 2009). Logo, ou a qualidade está presente em dada situação ou não está. Por isso é muito importante dar visibilidade a qualidade.

No ano de 1995 as instituições de ensino superior tiveram uma grande expansão e com isso tem-se sentido mais fortemente políticas educacionais as quais se apresentam por meio de regulamentações expedidas pelo poder público federal, que tem contribuído para a criação de mais instituições de ensino superior.

Segundo Leme (1983), Engenharia de produção possui algumas particularidades distintas tendo em vista os demais ramos da engenharia que requer serem apresentados em sua história. A primeira particularidade foi a crise da identidade da Engenharia de Produção no Brasil que andou conjunta a engenharia por muito tempo em seu desenvolvimento. Em meados anos 70 e 80 sempre surgiu questionamentos sobre o que os profissionais de engenharia de produção iria fazer. Ainda de acordo com Leme (1983), três definições que tiveram uma grande aceitação sobre o que o profissional de engenharia de produção iria atuar, que são: Primeiro Engenharia de métodos, que iria dar apoio e está presente em todos os métodos que fossem utilizados; logo em seguida destaca-se o campo que era onde iria se afunilar os conhecimentos de outras engenharias com as áreas administrativas e econômicas e por fim o campo específico, que se define por integração de estudo, análise e projeto de sistemas feito por homens, materiais e equipamentos, informações e ambiente.

A segunda particularidade é que a Engenharia de Produção não teria que encontrar-se membra de nenhum setor industrial em particular, pois o seu campo de atuação é muito vasto e trata de vários setores da economia, abrangendo o primário e o terciário. Segundo Schethtman (BRASIL, 1977, p. 310), Engenharia de produção se diferencia das demais devido não ser ligado a apenas um determinado tipo de sistema como Mecânico, elétrico, e sim abrangendo várias atividades. 
A terceira particularidade é inexistência de eventos consideráveis como obras da Engenharia Civil. Tendo em vista estas obras destaca-se a companhia brasileira Correios e Telégrafos que não tinha pleno funcionamento até a chegada da Engenharia de Produção, onde foi feito o planejamento das suas operações logísticas e conseguiu o êxito.

\section{METODOLOGIA}

O presente trabalho tem como finalidade analisar a percepção dos discentes em relação ao curso de Engenharia de Produção quanto a qualidade do curso ofertado pela Universidade Federal Rural do Semiárido, Campus Angicos-RN.

O Campus Angicos nasceu no ano de 2008 por meio do Programa de Reestruturação e Expansão das Instituições Federais de Ensino Superior (REUNI) e as suas atividades acadêmicas iniciaram em março de 2009. Nos dias de hoje a UFERSA - Campus Angicos oferta seis cursos de graduação sendo eles: Interdisciplinar em Ciência e Tecnologia (integral e noturno), bacharelado em Sistemas de Informação, Licenciatura em Computação e Informática, Engenharia Civil, Engenharia de Produção e Pedagogia.

O curso de Engenharia de Produção deu início as suas atividades em janeiro de 2014. Na atualidade conta com 65 alunos ativos, 12 professores efetivos e 4 professores substitutos e possui uma carga horária total de 3.780 horas. Vale ressaltar que o curso ofertado pela UFERSA é de segundo ciclo, ou seja, os discentes escolhem a engenharia após conclusão do curso de primeiro ciclo (Interdisciplinar em Ciência e Tecnologia).

Para a Pesquisa foram analisados os discentes que compõem o curso de engenharia de produção totalizando 65 discentes. A pesquisa contou com 56 respondentes o qual conferia a $5 \%$ de margem de erro e $95 \%$ de confiabilidade, a Equação (1) mostra a fórmula utilizada para efetuação do cálculo e ter o valor do tamanho da amostra.

$$
\text { Tamanho da Amostra }=\frac{\frac{z^{2} x p(1-p)}{e^{2}}}{1+\left(\frac{z^{2} x p(1-p)}{e^{2} x N}\right)}
$$

Sendo: $\mathrm{N}=$ Tamanho da população, $e=$ Margem de erro (porcentagem no formato decimal) e $z=$ Escore $z$. O escore z é o número que corresponde ao desvio padrão entre determinada porção e a média, para achar o z consulta-se a Tabela 1:

Tabela 1 - Grau de confiança

\begin{tabular}{|l|c|c|c|c|c|}
\hline Grau de Confiança & $80 \%$ & $85 \%$ & $90 \%$ & $95 \%$ & $99 \%$ \\
\hline Escore z & 1,28 & 1,44 & 1,65 & 1,96 & 2,58 \\
\hline
\end{tabular}

Para a coleta dos dados da pesquisa foi elaborado um questionário, composto por questões objetivas e questões abertas para que o discente pudesse se expressar, enviado via e-mail, foi solicitado a coordenação do curso que fosse feito o envio pelo e-mail da coordenação atingindo o público e também pelas mídias sociais para os participantes.

O questionário foi dividido em 3 partes. A primeira parte foi composta por questões que visavam a atuação dos docentes. A segunda parte continha perguntas relacionadas a infraestrutura e a terceira parte correspondeu a avaliação da estrutura curricular ofertada pelo curso.

Após a aplicação do questionário, foi feita a análise para interpretar a opinião dos discentes em relação ao curso, tendo em vista as três partes o qual foi dividido o questionário para saber o quanto estão satisfeitos com o curso de Engenharia de Produção UFERSA campus Angicos. 
"Os desafios para formar hoje o engenheiro do amanhã"

\section{RESULTADOS E DISCUSSÕES}

Inicialmente visando mostrar a percepção dos discentes em relação ao corpo docente do curso de Engenharia de Produção do Campus UFERSA Angicos, 8 questionamentos foram levantados sobre a atuação dos mesmos.

O primeiro questionamento é sobre o programa da disciplina, onde o discente deixou explicito a sua visão.

De acordo com as respostas obtidas, $4,57,1 \%$ da população de amostra atribuiu nota $4 \mathrm{o}$ qual representa a modalidade "Bom" quando se fala em relação aos docentes apresentarem o programa da disciplina, ou seja, os discentes afirmaram que a grande maioria dos docentes fazem a leitura e apresentam de forma detalhada o que vai se passar em sala de aula em relação ao conteúdo a ser abordado durante o semestre.

O segundo questionamento é sobre a avaliação de como o docente repassa o conteúdo para os seus discentes. Conforme o gráfico 5 apenas 2 discentes responderam que os docentes não deixavam claro o conteúdo resultando em $3,6 \%$ da amostra, o dado que chamou maior atenção foi o de nota 4 que conteve $65,5 \%$ dos votos.

O terceiro questionamento é sobre a avaliação do cumprimento do horário de suas aulas. Como mostra no gráfico 6 , apenas 3 discentes responderam que os docentes não cumpriam com os horários de sala aula representando $5,4 \%$ da amostra. $\mathrm{O}$ dado que chamou atenção foi o de nota 4 representando que os docentes cumprem os horários das aulas, totalizando $42,9 \%$ dos votos.

O quarto questionamento, diz respeito a clareza e objetividade na abordagem do conteúdo. Como mostra o gráfico 7 , apenas 3 discentes afirmaram que os docentes não mostram clareza e objetividade na abordagem dos conteúdos representando 5,4\% da amostra. $\mathrm{O}$ dado de número 4 chamou atenção tendo a maior votação, responsável por $57,1 \%$ dos votos demonstrando assim que os docentes transmitem com clareza e objetividade o conteúdo.

O quinto questionamento diz respeito ao esclarecimento de dúvidas. Como mostra o gráfico 8,8 discentes consideraram a alternativa 3 resultando assim em 14,3\% dos votos, já a alternativa de número 5 teve $55,4 \%$ dos votos o qual demonstra que os docentes esclarecem as dúvidas com excelência.

O sexto questionamento diz respeito à segurança ao transmitir o conteúdo para os seus discentes. Como mostra o gráfico 9, houve apenas uma resposta com a nota 2 representando $1,8 \%$. A alternativa de número 5 foi a de maior escolha, representando $51,8 \%$ dos votos, ou seja, os docentes apresentam uma enorme segurança em transmitir o conhecimento para os seus discentes.

O sétimo questionamento se refere ao incentivo dos docentes em relação aos discentes terem uma participação ativa em sala de aula, ou seja, fazer com que o docente discuta o conteúdo de forma dinâmica com todos que estão ali presentes. O gráfico 10 representa os números coletados na pesquisa. Houve apenas uma resposta com a nota 2 que representa apenas $1,8 \%$ do público e corresponde que o docente não incentiva a participação, já as notas 4 e 5 tiveram índices parecidos, os quais demonstram que o corpo docente incentiva os alunos se fazerem presentes nos debates em sala de aula.

O oitavo e último questionamento da avaliação dos docentes diz respeito a atuação em relação a comentários de resultados das avaliações. Conforme o gráfico 11, houve apenas uma resposta dando como nota 1 correspondendo a $1,8 \%$ dos votos o que diz respeito que este discente está muito insatisfeito. A alternativa de número 5 obteve $48,2 \%$ dos votos o qual comprova que os docentes fazem comentários e discutem com seus alunos as avaliações.

A Tabela 2 apresenta a análise geral da visão dos discentes quanto ao corpo docente do curso. 
"Os desafios para formar hoje o engenheiro do amanhã"

\section{Evento On-line}

Tabela 2 - Análise geral dos discentes quanto ao corpo docente do curso

\begin{tabular}{|l|c|c|c|c|c|}
\hline & $\begin{array}{c}(1) \\
\text { Péssimo }\end{array}$ & $\begin{array}{c}(2) \\
\text { Ruim }\end{array}$ & $\begin{array}{c}(3) \\
\text { Neutro }\end{array}$ & $\begin{array}{c}(4) \\
\text { Bom }\end{array}$ & $\begin{array}{c}(5) \\
\text { Excelente }\end{array}$ \\
\hline $\begin{array}{l}\text { Transmitem claramente aos alunos o programa } \\
\text { da disciplina }\end{array}$ & 0 & 1 & 9 & $\mathbf{3 2}$ & 13 \\
\hline Torna claro o conteúdo para os alunos & 0 & 2 & 11 & $\mathbf{3 6}$ & 6 \\
\hline Cumprimento do horário das aulas & 0 & 3 & 9 & $\mathbf{3 2}$ & 11 \\
\hline $\begin{array}{l}\text { Clareza e objetividade na abordagem do } \\
\text { conteúdo }\end{array}$ & 0 & 0 & 8 & 16 & $\mathbf{3 1}$ \\
\hline Dúvidas dos alunos esclarecidas & 0 & 1 & 3 & 22 & $\mathbf{2 9}$ \\
\hline Segurança ao transmitir conhecimento & 0 & 1 & 9 & 20 & $\mathbf{2 5}$ \\
\hline Comentários com os alunos sobre as avaliações & 1 & 3 & 7 & 17 & $\mathbf{2 7}$ \\
\hline
\end{tabular}

Fonte: Esta pesquisa

A avaliação dos discentes em relação a infraestrutura presente na UFERSA Campus Angicos tendo como objetos de avaliação: sala de aula, laboratório, biblioteca, restaurante universitário, centro de convivência e secretaria.

Assim, em relação a climatização das salas de aula, observa-se que a alternativa de número 2 obteve $10,7 \%$ dos votos, o qual representa o público que está insatisfeito com a climatização. A alternativa de número 4 teve a maior votação atingindo assim 48,2\% dos votos, o que significa que os discentes estão satisfeitos com a climatização existente nas salas de aula.

Ainda falando sobre a sala de aula, entra em questão outro fator que é a iluminação. Temse que 8 discentes assinalaram a alternativa 3 representando assim 14,3\% do público. Os demais respondentes ficaram divididos entre as alternativas de nota 4 e 5 os quais demonstram que as salas de aula têm uma boa iluminação. Outro fator é a acústica das salas de aula. Assim, observando as respostas pode-se notar que 3,6\% dos discentes avaliaram que a acústica das salas de aula é péssima, dando assim nota 1. A alternativa de número 4 teve maior votação estando assim com 36,4\% dos votos, com isso, mostra que a acústica das salas de aulas é boa.

Quanto a avaliação da modalidade de serviços gerais oferecidos pelo campus. Isto é, a limpeza nas salas de aula $8,9 \%$ dos discentes deram nota 3 . A alternativa de número 5 que comprova que é excelente obteve $64,3 \%$ dos votos mostrando assim que é de excelência a limpeza nas salas de aula. Outro fator analisado no quesito sala de aula foi a mobília oferecida pelo campus.

Pode-se observar que este é um dos fatores o qual tem uma grande subjetividade entre os respondentes. Logo, apenas um discente afirmou que a mobília oferecida pelo campus é de péssima qualidade, a avaliação que teve maior consideração foi a de nota 4 o qual 36,4\% dos discentes afirmaram que a mobília era de boa qualidade.

O último quesito analisado na modalidade das salas de aula foi a de espaço oferecido pelo Campus. As alternativas de avaliação com nota 1 e 2 tiveram apenas um respondente respectivamente o qual avalia que o espaço das salas de aula é péssimo e ruim respectivamente, as alternativas de número 4 e 5 tiveram destaque por terem os maiores números de votação o qual demonstra que os respondentes gostam e dizem que é de excelência o espaço das salas de aula. A avaliação geral dos discentes quanto as salas de aula são apresentadas na Tabela 3. 
"Os desafios para formar hoje o engenheiro do amanhã"

\section{Evento On-line}

Tabela 3 - Avaliação geral dos discentes quanto as salas de aula

\begin{tabular}{|l|c|c|c|c|c|}
\cline { 2 - 6 } & (1) Péssimo & (2) Ruim & (3) Neutro & (4) Bom & (5) Excelente \\
\hline Climatização de sala de aula & 0 & 6 & 16 & $\mathbf{2 7}$ & 7 \\
\hline Iluminação de sala de aula & 0 & 0 & 8 & $\mathbf{2 6}$ & 22 \\
\hline Acústica de sala de aula & 2 & 3 & 17 & $\mathbf{2 0}$ & 13 \\
\hline Mobília de sala de aula & 0 & 0 & 5 & 15 & $\mathbf{3 6}$ \\
\hline Espaço de sala de aula & 1 & 6 & 18 & $\mathbf{2 0}$ & 10 \\
\hline
\end{tabular}

Fonte: Esta pesquisa

Em seguida se inicia a avaliação em relação aos laboratórios oferecidos pela UFERSA Campus Angicos. Os quesitos analisados serão: climatização, iluminação, acústica, limpeza, mobília e equipamentos.

Observa-se que 3,6\% dos discentes assinalaram que a climatização dos laboratórios não é boa. A alternativa de número 4 obteve $41,8 \%$ dos votos o que significa que a climatização nos laboratórios está boa. Quanto a iluminação, nota-se que 3,6\% dos discentes afirmaram que os laboratórios não tinham boa iluminação, e os demais respondentes ficaram divididos entre as alternativas de nota 4 e 5 os quais demonstram que os laboratórios têm uma boa iluminação.

Observando a avaliação quanto a acústica dos laboratórios pode-se notar que apenas 1,8\% dos discente avaliaram que a acústica dos laboratórios é péssima dando assim nota 1 . A alternativa de número 4 , obteve $43,6 \%$ dos votos expondo que a acústica nos laboratórios da UFERSA campus Angicos têm uma boa qualidade. Quanto a limpeza, 3,6\% dos discentes se mostraram insatisfeitos dando nota 3 , já a alternativa de número 5 obteve $61,8 \%$ dos votos, o que significa que a limpeza dos laboratórios é de excelência.

Quanto o quesito mobília dos laboratórios oferecida pelo campus, observa-se que 10,9\% dos discentes afirmaram que a mobília dos laboratórios oferecida pelo campus é de péssima qualidade, a avaliação que teve maior consideração foi a de nota 4 o qual 45,5\% dos discentes afirmaram que a mobília era de boa qualidade.

Essa modalidade visa coletar a avaliação dos discentes em relação a qualidade dos equipamentos existentes no laboratório demonstra-se que 3,6\% dos discentes avaliaram este fator como de qualidade excelente. Tendo em vista o gráfico nota-se que a alternativa de número 3 obteve $52,7 \%$ dos votos o qual significa que está havendo uma insatisfação nos equipamentos do laboratório. A avaliação geral dos discentes quanto aos laboratórios é mostrada na Tabela 4.

Tabela 4 - Avaliação geral dos discentes quanto aos laboratórios

\begin{tabular}{|c|c|c|c|c|c|}
\hline & (1) Péssimo & (2) Ruim & (3) Neutro & (4) Bom & (5) Excelente \\
\hline Climatização dos laboratórios & 0 & 2 & 10 & $\mathbf{2 3}$ & 20 \\
\hline Iluminação dos laboratórios & 0 & 2 & 9 & $\mathbf{2 3}$ & 21 \\
\hline Acústica dos laboratórios & 1 & 4 & 13 & $\mathbf{2 4}$ & 13 \\
\hline Mobília dos laboratórios & 6 & 0 & 13 & 25 & $\mathbf{1 1}$ \\
\hline Equipamentos dos laboratórios & 6 & 7 & 29 & $\mathbf{1 1}$ & 2 \\
\hline
\end{tabular}

Fonte: Esta pesquisa 
Logo em seguida se inicia a avaliação em relação a Biblioteca da UFERSA Campus Angicos. Os quesitos analisados serão: climatização, iluminação, limpeza e acervo bibliográfico.

Pôde-se observar que $12,7 \%$ dos discentes assinalaram que a climatização das bibliotecas não é boa, $41,8 \%$ dos discentes afirmaram que a climatização é de boa qualidade obtendo a maior votação neste quesito. Em relação a iluminação da biblioteca nota-se que 5,4\% dos alunos não estão satisfeitos com a iluminação da biblioteca assinalando a alternativa de nota 2 . A alternativa de número 5 obteve 39,3\% dos votos assinalando que a iluminação da biblioteca é de excelência. Quanto a iluminação da biblioteca nota-se que 5,4\% dos alunos não estão satisfeitos com a iluminação da biblioteca assinalando a alternativa de nota 2 . A alternativa de número 5 obteve 39,3\% dos votos assinalando que a iluminação da biblioteca é de excelência. No quesito limpeza da biblioteca, 3,6\% dos discentes afirmaram não ser boa a limpeza na biblioteca, já na alternativa $5,54,5 \%$ dos discentes assinalaram que era de excelência a limpeza da biblioteca da UFERSA campus Angicos.

Quando se fala em biblioteca um dos quesitos mais importantes a ser analisado é em relação ao acervo bibliográfico presente. Logo, observa-se que 23,6\% dos discentes assinalaram que o acervo bibliográfico não é bom deixando a desejar em vários quesitos como: falta de livros, poucos exemplares e entre outros; 37,5\% dos discentes estão insatisfeitos e apenas 12,5\% dos discentes assinalaram que era de excelência o acervo bibliográfico. A avaliação geral dos discentes quanto a biblioteca é apresentada na Tabela 5.

Tabela 5 - Avaliação geral dos discentes quanto a biblioteca

\begin{tabular}{|c|c|c|c|c|c|}
\hline & (1) Péssimo & (2)Ruim & (3) Neutro & (4) Bom & (5) Excelente \\
\hline Climatização da biblioteca & 0 & 7 & 12 & $\mathbf{2 3}$ & 13 \\
\hline Iluminação da biblioteca & 0 & 3 & 12 & 19 & $\mathbf{2 3}$ \\
\hline Limpeza da biblioteca & 0 & 2 & 4 & 19 & $\mathbf{3 0}$ \\
\hline Acervo Bibliográfico & 2 & 8 & 21 & $\mathbf{1 8}$ & $\mathbf{7}$ \\
\hline
\end{tabular}

Fonte: Esta pesquisa

Os discentes apontaram que a grade curricular e carga horária estão adequadas escolhendo a opção 4 que obteve o maior número de votos. Conforme é apresentado na Tabela 6.

Tabela 6 - Avaliação da Estrutura Curricular do curso

\begin{tabular}{|c|c|c|c|c|c|}
\hline & (1) Péssimo & (2) Ruim & (3) Neutro & (4) Bom & (5) Excelente \\
\hline Ementa do curso & 0 & 4 & 9 & $\mathbf{2 7}$ & 15 \\
\hline Carga horária do curso & 1 & 2 & 10 & $\mathbf{2 9}$ & 14 \\
\hline
\end{tabular}

Fonte: Esta pesquisa

\section{CONSIDERAÇÕES FINAIS}

Após a análise dos dados obtidos através do questionário chegou-se a conclusão de que os professores do curso de engenharia de produção estão altamente capacitados, pois conseguem repassar o conteúdo com clareza, demonstra clareza e objetividade na abordagem do conteúdo, esclarece dúvidas dos alunos, consegue transmitir o conteúdo com clareza para o discente, fazem uso de metodologias ativas os quais chamam maior atenção do aluno fazendo com que ele tenha uma melhor aprendizagem. 
Quanto a infraestrutura do campus em que contém o curso que foi julgado pelos discentes, tem-se a seguir as afirmativas com maior frequência nas respostas de alternativa 4 que significa "Bom" e alternativa 5 que significa "Excelente".

Conforme as repostas dos alunos, tem-se que as salas de aula estão suprindo todas as necessidades tendo como destaque de satisfação os quesitos de climatização, iluminação, limpeza.

Tem-se que laboratórios estão suprindo as necessidades tendo como melhorias o investimento de novas máquinas e iniciar a fazer o uso do novo laboratório para que os discentes tenham mais práticas o qual é de grande importância. Destaque de satisfação dos respondentes os quesitos de climatização, iluminação, limpeza e acústica.

Tendo em vista as respostas dos discentes em relação a biblioteca, algumas melhorias devem serem executadas como a aquisição de um novo acervo bibliográfico o qual falta na biblioteca e a aquisição de mais exemplares dos livros que tem maior frequência de empréstimos suprindo assim uma necessidade dos alunos. Quesitos foram elogiados em relação a biblioteca que foram os de limpeza e iluminação. Conforme as respostas em relação a estrutura curricular do curso de engenharia de produção os discentes estão satisfeitos não deixando a desejar em nenhum quesito.

Assim, conclui-se que o curso de engenharia de produção no geral, apresentou uma ótima avaliação por parte dos discentes, demonstrando ser um curso com qualidade, que apresenta uma boa infraestrutura de maneira geral, além de possuir um corpo docente engajado e comprometido com o desenvolvimento e crescimento acadêmico e profissional de seus alunos.

\section{REFERÊNCIAS}

BARBETTA, Pedro Alberto et al. Estatística para Cursos de Engenharia e Informática. Editora Atlas. 2004.

BERTOLIN, J. C. G. Indicadores em nível de sistema para avaliar o desenvolvimento e a qualidade da educação superior brasileira. Revista Avaliação, Sorocaba. v. 12, n. 2, p. 309331, jun. 2007.

BRASIL. Senado Federal. Resolução no. 10/77 de 27 de abril de 1977. LEX: Coletânea de legislação e jurisprudência. São Paulo.

CARPINETTI, L. C. R. Gestão da Qualidade: Conceitos e Técnicas. 2. ed. São Paulo: Atlas, 2012.

DAVOK, D. F. Qualidade em educação. Revista Avaliação. v. 12, n. 3, p. 505-513, set. 2007. Campinas: Sorocaba, SP.

DIAS SOBRINHO, José. Avaliação e transformações da educação superior brasileira (19952009): do provão ao Sinaes. Revista Avaliação (Campinas, vol. 15, n. 1, Sorocaba, 2010.

MOREIRA, E.G.; MOREIRA, T.G.; MARTINS, D.D.S., Aplicação da ferramenta de qualidade PDCA para a solução de problemas críticos em empresa panificadora. Anais. IX Simpósio Acadêmico de Engenharia de Produção, Universidade Federal de Viçosa, Viçosa, MG, 20 a 22 de Nov. 2014. 
CORRÊA, H. L. The Links between Uncertainty, Variability of Outputs and Flexibility in Manufacturing Systems. University of Warwick, Warwick, 2002.

QUEIROZ, J.V; QUEIROZ, F. C. B. P; HEKIS, H. R. Strategic and financial management of higher education institutions: Case study. Iberoamerican Journal of industrial Engineering, v.1, p. 98-117, 2011.

CAMPOS, V. F. Gerenciamento da rotina de trabalho do dia-a-dia. Nova Lima: INDG Tecnologia e Serviços Ltda, 2004.

JURAN, J.M.. A qualidade desde o projeto: Os novos passos para o planejamento da qualidade em produtos e serviços. 3 ed. São Paulo: Ed. Pinoneira,1992.

\title{
ANALYSIS OF THE PERCEPTION OF QUALITY IN HIGHER EDUCATION: A VIEW FROM THE DISCENTS OF THE PRODUCTION ENGINEERING COURSE AT UFERSA CAMPUS ANGICOS
}

\begin{abstract}
The evaluation of the quality of higher education from the student's perspective is a key factor for the academic management of undergraduate courses and educational institutions. In this context, the present study aims to analyze the perception of the Production Engineering course in the students' view. The methodological classification of the research as to its character is defined as field research, in which an online questionnaire was drawn up and applied that reached $95 \%$ of its target audience, in order to analyze or measure the degree of satisfaction of the students in relation to the faculty, infrastructure and curriculum. This evaluation allowed to identify a perspective of higher education, with emphasis on the production engineering course at UFERSA Campus Angicos so that or degree of student satisfaction in relation to the performance of the teachers, the infrastructure and the curriculum note are presented.
\end{abstract}

Keywords: University education. Production engineering. Students. Evaluation. 